\title{
Public perceptions of internet, familial and localised sexual grooming: Predicting perceived prevalence and safety
}

\author{
Matthew L. Williams* \& Kirsty Hudson \\ Cardiff University, School of Social Sciences, Cardiff, UK
}

\begin{abstract}
This paper examines public perceptions of three sexual grooming types: computer-mediated sexual grooming (CMSG), familial sexual grooming (FSG) and localised sexual grooming (LSG). Using data from a national survey of 557 respondents from the United Kingdom, we tested models that predicted perceptions of the prevalence of CMSG, FSG and LSG and the perceived safety of internet, familial and localised grooming spaces. Media-related factors were the most significant in predicting bigher levels of perceived prevalence of CMSG and disagreement in relation to safety of internet and public spaces. Knowledge of a grooming victim was most significant in predicting higher levels of perceived prevalence of FSG and LSG and higher levels disagreement in relation to the safety of the bome. The findings suggest that the public express too little concern over familial sexual grooming and that initiatives should be introduced to make citizens more aware of the distinctions between types of sexual grooming behaviours, settings and offenders.
\end{abstract}

Keywords computer-mediated sexual grooming; familial sexual grooming; localised sexual grooming; media and sexual grooming

\section{Introduction}

Grooming has been established as a significant part of the cycle of sexual abuse (Finkelhor, 1984; Hall \& Hirschman, 1992; Ward, 2002; Ward \& Siegert, 2002; Wolf, 1984), yet there remains substantial debate about what accurately constitutes sexual grooming behaviour (Craven, Brown, \& Gilchrist, 2006). Ost (2009, p. 34), for example, defines sexual grooming as "any behaviour that is designed to build up a relationship of trust with a child with the longer-term goal of involving the child in some sexually related act or acts". The grooming behaviours used by individuals that could constitute sexual grooming are thus wide and diverse. Grooming by strangers "on the streets" has been subject to considerable media and legislative attention over the last decade. The thematic review conducted by the Child Exploitation and Online Protection Centre (CEOP), which examined the occurrence of "localised grooming", was carried out after "a series of high profile cases of child sexual exploitation in the UK were covered in the media" (CEOP, 2011, p. 10). More recently, sexual grooming via the internet has taken centre stage in media, policy and academic debate

*Corresponding author: E-mail: williamsM7@acf.ac.uk 
(O’Halloran \& Quayle 2010; Quayle, 2008; Taylor \& Quayle, 2008). In particular, interim findings from the European Online Grooming Project highlight the key role that Web2.0 technologies, such as social media platforms, play in the offence cycle (Webster, Davidson, \& Bifulco, 2011). Furthermore, section 15 of the Sexual Offences Act 2003, referred to as the "grooming offence", was implemented after increasing concern over the sexual grooming of children via the internet and essentially legislates against grooming that has occurred online ${ }^{1}$. Despite the attention provided to these types of grooming in the various domains, there remains a dearth of understanding of how different forms of sexual grooming are perceived by the general public and how these perceptions impact upon behaviours. This paper explores computer-mediated sexual grooming (CMSG), familial sexual grooming (FSG) and localised sexual grooming (LSG) in terms of how the public perceive their prevalence and the safety of internet, familial and localised grooming spaces.

For the purposes of this study, CMSG captures grooming behaviours conducted via the internet ${ }^{2}$ (Quayle, 2008). A distinction is then made between two types of non-internet "face-to-face" grooming behaviours, taking into account the offender-victim relationship. As in the recent CEOP (2011) report, LSG was used to define grooming where the offender is initially unknown to the victim, and meets his/her victim in a public place. FSG was then used to define cases where the offender is known to the victim, and the grooming takes place routinely in situational settings known to the child, such as the home. Cases of intrafamilial and quasi-intrafamilial abuse were captured within the FSG definition. We recognise that these definitions cannot be divorced completely from one another, as while grooming may begin face to face, the internet (as well as other online technologies ${ }^{3}$ ) may then be used and provide new grooming methods and outcomes, and vice-versa.

Based on previous research, we identified a number of potential predictors that have been proved to impact upon the perceptions of crime, and specifically sexual crime, including various media output and knowledge/experience of sexual grooming factors (Brayford \& Deering, 2012; Davidson, 2008; Farrell \& Soothill, 2001; Kitzinger, 2004).

\section{Contexts}

\section{Defining sexual grooming}

This paper addresses public perceptions of sexual grooming (prevalence and safety) and how these vary by location (face-to-face: localised and familial; and computer-mediated: online sites). This section provides a brief overview of (a) how sexual grooming manifests in each of these spaces and (b) existing research on perceptions of perpetrators and their behaviours.

Face-to-face sexual grooming interactions. In the same way that the representation of stranger-danger continues to dominate media reporting and public consciousness, arguably face-to-face grooming is associated mainly with grooming of children by strangers, defined in this study as LSG. However, face-to-face grooming can, and is also more likely, to occur within the home and by someone who is known to the victim, defined in this study as FSG. In both instances the grooming behaviours employed might include buying the child gifts, sweets, alcohol or drugs. In LSG this may be used to establish an inappropriate (boyfriend/girlfriend) "relationship" (CEOP, 2011). However, in FSG a relationship, and very often a good relationship, will already exist (Craven et al., 2007). In these instances, grooming techniques are used to make the abuse seem acceptable and even "consensual", at least in the offenders' eyes (Hudson, 2005). Consequently, in all cases of face-to-face grooming, it can become difficult (especially for the victim) to distinguish between sexually motivated 
grooming behaviours and perfectly normal interactions between an adult and a child. As Craven et al. (2007, p. 64) state 'The offender may simply appear to be a 'nice man', who takes an interest in children, and who is willing to spend time doing the jobs that other adults do not want to do or have the time to do".

Computer-mediated sexual grooming interactions. CMSG provides more distinguishable beha-viours compared to face-to-face grooming. The internet provides a high degree of anonymity, enabling offenders to masquerade as "desirables" in order to facilitate relationships with children (Quayle, 2008; Taylor \& Quayle, 2008). Offenders are therefore able to adopt children's online idiolect ${ }^{4}$ to masquerade as "one of them" and learn about their interests and hobbies. These deliberate tactics are used to establish trust that can then be misused and betrayed through abuse (Davidson \& Gottschalk, 2011; Davidson \& Martellozzo, 2008; Gillespie, 2004; Jewkes, 2007; Martellozzo, 2011a, b; Ost, 2009). Combined with the perceived vast distances between online interlocutors (victim and offender), these factors create a deindividuating effect resulting in increased risk taking on the part of both the offender and the victim (Joinson, 1998; Webster et. al., 2010; Williams, 2006). Grooming over the internet is therefore highly synonymous with stranger abuse, a conflation often reinforced by the tabloid media.

\section{Public perceptions}

Research that focuses specifically on public perceptions of sexual offending frequently shows contradictory attitudes (Levenson, Brannon, \& Baker, 2007; McCarten, 2004; Olver \& Barlow, 2010). Levenson et al.'s (2007, p. 19) respondents supported the "myths of extraordinarily high recidivism rates and stranger danger", yet McCartan's (2004) partici-pants' perceptions of "paedophiles" showed that the majority felt that the "home" could potentially be the most dangerous place for a child. Regardless of these asymmetrical findings, there is the general acceptance that the public tend to hold inaccurate, stereotyped and skewed perceptions about sex offenders and offending, similar to those depicted in the media. Almost uniquely, McCartan's conclusions suggest that the public have the capacity to "disengage" from the media's image that sexual crimes are committed exclusively by strangers. Alternatively, one may assume that while the public accept that the chance of being sexually abused by a stranger is slight, they are still reluctant to conceptualise the risk of sexual victimisation in domestic terms, which would ultimately undermine the conventional views of the family and the home (Greer, 2003; Hudson, 2005).

Several studies have also focused on public perceptions towards the manner in which sex offenders are dealt with by criminal justice agencies. Unsurprisingly, most demonstrate a punitive attitude towards sex offenders (see, for example, Brown, Deakin, \& Spencer, 2008; Levenson et al., 2010; Zamble \& Kalm, 1990; Zilney \& Zilney, 2009). In particular, the public are seen to be in favour of full public disclosure of information about registered sex offenders (News of the World, 2005; Proctor, Badzinski, \& Johnson, 2002; Schiavone \& Jeglic, 2009). The suggested goal of full public disclosure is to increase the public's awareness of sex offenders and to help people protect themselves and their children from sexual abuse. It is thus primarily applicable to the threat posed by strangers. Support for such a scheme would therefore seem to support arguments that the public are overly concerned about "stranger danger".

Despite a lack of literature on public perceptions of sexual grooming per se, a finding that is pertinent to this research shows public perception towards policy to be highly influenced by sensationalised media reports (Zilney \& Zilney, 2009). Research has demonstrated that the 
media and personal experience/knowledge of crime plays an important role in shaping public perceptions of the crime problem (Davidson, 2008; Jewkes, 2004; Mohan, Twigg, and Taylor, 2011; Reiner, 2007). In particular, studies have evidenced the distortive effect of the tabloid media on public perceptions of sex crimes (Brayford \& Deering, 2012; Farrell \& Soothill, 2001; Greer, 2003; Jewkes, 2010; Kitzinger, 2004; Soothill \& Walby, 1991; Thakker 2012). The protests following the controversial "Name and Shame" campaign of convicted sex offenders, spearheaded by a Sunday tabloid, the News of the World, demonstrate clearly the emotive public reaction to sex offending and sex offenders and subsequent calls for public disclosure (Silverman \& Wilson, 2002). In the same way, tabloid media distortions of grooming via the internet and localised grooming can act to distract readers from the complexities of grooming behaviour, and according to Ost (2009, p. 138) "direct attention away from the situational settings in which children are more likely to be groomed for sexual abuse". Indeed, despite the apparent "stranger-danger" bias in tabloid media reporting of sexual crime, the fact remains that the vast majority of abuse takes place by someone known to the victim, and most often offline (Car, 2004; Flatley, Smith, Chaplin, \& Moon, 2010; Stop it Now, 2003).

Based on this research evidence, it is reasonable to hypothesise that the inaccurate and misleading presentation of CMSG and LSG and the relative lack of reporting on FSG in the tabloid media will influence public perception of their prevalence and the safety of online, familial and localised potential grooming spaces. In turn, this misconception will have clear implications for the success of prevention efforts. Craven et al. (2007, p. 66), for example, suggest that "the public may believe that because of the new provision provided by the Sexual Offences Act 2003, child sex offenders present less risk to themselves and their families, and thus be less vigilant in light of this". Perhaps more worryingly, due to heightened concern over stranger danger, it is also "probable that children will be more vulnerable to other more common forms of grooming because parents are less aware of the situations and circumstances in which children are most at risk" (Ost, 2009, p. 138). The tabloid media reaction after a high profile case involving LSG also succeeds in removing child sexual grooming from the lives of most people. LSG is seen to be a key stage in child exploitation. It therefore also becomes associated invariably with particularly vulnerable children; for example, children with a history of running away from home, children who are disengaged from education and/or looked-after children (children in local authority care) (CEOP, 2011). It also presents depictions of the "predatory sex offender" and the "anonymous stranger" (Farrell \& Soothill, 2001; McCartan, 2010; Sampson, 1994; Silverman \& Wilson, 2002; Soothill \& Walby, 1991), disguising the reality that the majority of sex offenders are friends, family and loved ones (Flatley et al., 2010). The ability of the public to correctly identify and recognise grooming behaviours and offenders depends on their understanding of the different types of behaviours and methods that this can involve.

\section{Hypotheses}

H1: Media consumption factors will be associated positively with perceptions of prevalence of CMSG and LSG

Based on the aforementioned research we postulated that media-related variables would have a significant positive impact upon respondent perceptions of the prevalence of CMSG and LSG (more likely to perceive as highly prevalent). 


\section{H2: Knowledge of a grooming victim will be associated positively with perceptions of prevalence of FSG}

Correspondingly, given the lack of reporting with respect to familial cases of grooming, we postulated that media-related variables would not have an impact on perceptions of FSG prevalence. Instead, we postulated that knowledge of a grooming victim would have a positive impact upon perceptions of FSG prevalence.

\section{H3: Media consumption factors will be associated negatively with perceptions of safety of computer-mediated and localised spaces}

We postulated further that media-related variables would have a significant negative impact upon respondent perceptions of the safety of computer-mediated (online sites) and localised spaces (public spaces) in relation to sexual grooming (more likely to disagree spaces are safe).

\section{H4: Knowledge of a grooming victim will be associated negatively with perceptions of safety of familial spaces}

Correspondingly, media-related variables would not be significant in predicting the per-ceived safety of familial spaces (the home). Instead, we postulated that knowledge of a grooming victim would have a significant predictive impact upon the perceived safety of familial spaces.

\section{Methods of analysis}

\section{Data}

Given the nascence of grooming legislation in the United Kingdom, it is not surprising to note that no version of the British Crime Survey includes questions on the topic, nor does any other publically accessible national data set. The primary data used in this analysis were derived from an online survey of 557 members of the public in the United Kingdom. The Bristol Online Survey tool ${ }^{5}$ was used to design and distribute the questionnaire via e-mail, social networks and online forums for parents ${ }^{6}$. The use of online media in social research is now well established and can yield results for exploratory research in a short period of time (Fielding, Lee, \& Black, 2008). Non-probability sampling was employed to derive the sample of respondents. While sample bias is a fundamental shortcoming of non-probability sampling, Meyer and Wilson (2009) note that this is often the only option available to researchers embarking on exploratory research. Furthermore, as the hypotheses tested in this analysis are concerned more with the existence of intervariable relations and strengths of association than estimating population prevalence ${ }^{7}$, the use of non-probability sampling does not fundamentally weaken the design of the study (Dorofeev \& Grant, 2006). Moreover, our study is concerned principally with "soft" measures (attitudes, perceptions, opinions), which have no absolute validity (they cannot be compared with any authoritative external measure). Meyer and Wilson (2009) caution that sampling bias can still affect hypothesis testing if a sample is significantly uncharacteristic of the target population. Selective targeting was employed during survey recruitment to mitigate this potential problem. In particular, we were cognisant of the need to map our sample onto the general population's characteristics (gender, age, income, etc.) where possible. 
The research was conducted in line with the ethical guidance established by the Association of Internet Researchers ${ }^{8}$. Given the nature of the research topic, the authors made efforts to establish informed consent via the introduction page to the online survey. The research aims and objectives were expressed clearly and all respondents were informed that the data produced would be anonymised and would remain confidential. Those aged under 16 years were not permitted to complete the survey.

\section{Measures}

Dependent variables. To test the hypotheses several dependent variables were identified in relation to perceived prevalence of grooming and safety of potential grooming spaces. Perception of CMSG, FSG and LSG prevalence were measured by a set of ordinal items. Respondents were asked to indicate on a four-point Likert scale how common they perceived the three types of grooming were in the United Kingdom at the time of the survey. To measure perception of the safety of CM (the internet), familial (the home) and localised spaces (public places) in relation to sexual grooming, respondents were asked to indicate their level of agreement with a set of statements on a four-point Likert scale. Reliability analysis showed a high degree of internal consistency between the respective item sets indicating common underlying constructs (prevalence: Cronbach's a .79; safety of spaces: Cronbach's a .80 ).

\section{Predictor variables}

Table I reports the descriptive statistics for the predictor variables used in the ordered regression analyses reported later in the paper.

Media. Two survey items provided details on respondents' consumption of media outputs. The first gathered data on respondents' primary media source for crime information [newspapers (including online), television or personal experience]. The second item generated data on the type of newspaper read most frequently by respondents (tabloid or broadsheet). Based on previous research on the impact of media upon perceptions crime, we postulated that these two items would emerge as significant in predicting perceived prevalence of CMSG and LSG as well as perceived safety of CM and localised potential grooming spaces.

Knowledge of grooming victimisation. One survey item measured respondents' knowledge of grooming victimisation. The question asked respondents if they knew of any children of friends or family who had been subject to sexual grooming in their lifetime. We postulated that this item would not emerge as significant in predicting perceived prevalence of CMSG and LSG or perceived safety of potential CM and localised grooming spaces. However, we did postulate that it would emerge as significant in relation to perceived prevalence of FSG and safety of familial grooming spaces. This was based on the research by Ost (2009), which indicated that those who have been groomed are most likely to have been exposed to FSG, which would be reflected in respondents' perceptions.

Internet. One item elicited data on respondents' internet expertise. This was a continuous variable that ranged from 1 (low expertise) to 10 (high expertise). Due to a lack of literature 
Table I. Descriptive and bivariate statistics—respondent characteristics by perceived grooming prevalence $(\mathrm{n}=557)$.

\begin{tabular}{|c|c|c|c|c|c|c|c|c|c|}
\hline \multirow[b]{2}{*}{ Independent variables } & \multirow[b]{2}{*}{ Coding } & \multicolumn{2}{|c|}{ Sample } & \multicolumn{2}{|c|}{ CMSG } & \multicolumn{2}{|c|}{ FSG } & \multicolumn{2}{|c|}{ LSG } \\
\hline & & $\mathrm{N} / \mathrm{M}$ & $\%$ a $/$ s.d. & $M(1-4)$ & $\mathrm{Z} / \chi^{2}(\mathrm{df})$ & $M(1-4)$ & $\mathrm{Z} / \chi^{2}(\mathrm{df})$ & $M(1-4)$ & $\mathrm{Z} / \chi^{2}(\mathrm{df})$ \\
\hline \multirow[t]{3}{*}{ Crime info. source } & $1=$ newspapers & 155 & 28.7 & 2.93 & $3.81(2)^{\star}$ & 1.86 & $3.23(2)^{\star}$ & 2.44 & $2.45(2)$ \\
\hline & $2=$ television & 325 & 60.2 & 3.08 & & 1.98 & & 2.58 & \\
\hline & $3=$ personal experience & 60 & 11.1 & 3.02 & & 1.87 & & 2.55 & \\
\hline \multirow[t]{3}{*}{ Newspaper } & $0=$ tabloid & 218 & 41.1 & 3.15 & $-3.09(2)^{\star \star}$ & 1.98 & $3.325(2)^{\star}$ & 2.62 & $4.56(2)^{\star \star}$ \\
\hline & $1=$ broadsheet & 204 & 38.5 & 2.90 & & 1.84 & & 2.40 & \\
\hline & $2=$ do not read a paper & 108 & 20.4 & 2.95 & & 1.91 & & 2.49 & \\
\hline \multirow[t]{2}{*}{ Knowledge of grooming } & $0=$ no & 474 & 85.6 & 3.01 & $-1.18(1)$ & 1.89 & $-2.14(1)^{\star \star}$ & 2.49 & $-2.73(1)^{\star \star \star}$ \\
\hline & $1=$ yes & 80 & 14.4 & 3.09 & & 2.10 & & 2.76 & \\
\hline \multirow[t]{2}{*}{ Ethnicity } & $0=\mathrm{BME}$ & 25 & 4.6 & 3.20 & $-1.09(1)$ & 1.72 & $-1.83(1)^{\star \star}$ & 2.36 & $-1.23(1)$ \\
\hline & $1=$ white & 520 & 95.4 & 3.01 & & 1.93 & & 2.51 & \\
\hline \multirow[t]{2}{*}{ Sex } & $0=$ female & 389 & 70.6 & 3.10 & $-3.11(1)^{\star \star \star}$ & 1.97 & $-3.21(1)^{\star \star \star}$ & 2.61 & $-4.00(1)^{\star \star *}$ \\
\hline & $1=$ male & 162 & 29.4 & 2.85 & & 1.80 & & 2.33 & \\
\hline \multirow[t]{2}{*}{ Children } & $0=$ no & 367 & 68.2 & 3.10 & $-3.01(1)^{\star \star \star}$ & 1.89 & $-1.76(1)^{\star \star}$ & 2.52 & $-0.18(1)$ \\
\hline & $1=$ yes & 171 & 31.8 & 2.85 & & 2.00 & & 2.52 & \\
\hline \multirow[t]{5}{*}{ Household income } & $1=$ below $10 \mathrm{k}$ & 78 & 15.2 & 3.24 & $11.20(4)^{\star \star}$ & 1.88 & $1.73(2)$ & 2.67 & $7.00(4)^{\star}$ \\
\hline & $2=10-20 \mathrm{k}$ & 77 & 15.0 & 3.16 & & 1.97 & & 2.60 & \\
\hline & $3=20-40 \mathrm{k}$ & 126 & 22.6 & 2.98 & & 1.94 & & 2.50 & \\
\hline & $4=40-60 \mathrm{k}$ & 109 & 21.2 & 2.88 & & 1.85 & & 2.53 & \\
\hline & $5=60 \mathrm{k}$ and above & 123 & 24.0 & 2.92 & & 1.94 & & 2.36 & \\
\hline \multirow[t]{3}{*}{ Age } & $1=16-21$ & 178 & 32.0 & 3.21 & $16.31(2)^{\star \star \star}$ & 1.81 & $5.28(2)^{\star \star}$ & 2.52 & $0.29(2)$ \\
\hline & $2=22-35$ & 149 & 27.1 & 2.97 & & 1.96 & & 2.51 & \\
\hline & $3=36$ and above & 222 & 40.4 & 2.90 & & 1.98 & & 2.53 & \\
\hline Internet experience & Range $=0-10$ & 7.5 & 1.7 & - & $11.59(9)$ & - & $9.58(9)$ & - & $14.32(9)$ \\
\hline
\end{tabular}

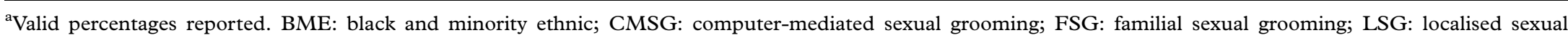
grooming; s.e.: standard error. ${ }^{\star} p=<.10 ;{ }^{\star \star} \mathbf{p}=<.05 ;{ }^{\star \star \star} \boldsymbol{p}<.01$. 
on the impact of internet expertise on perceptions of sexual grooming, we postulated that the item would have no significant predictive impact in the models.

Controls. Several items from the survey were included in the models as control variables. These included sex, ethnicity, parent, age and household income.

\section{Results}

\section{Descriptive and bivariate statistics}

Perceived grooming prevalence. Table I details general descriptive statistics on the sample of respondents as well as results from the bivariate analysis of prevalence variables. Of those who digested crime information from media outputs, the majority reported television as their primary source $(60.2 \%)$, followed by newspapers $(28.7 \%)$ and personal experience ${ }^{9}(11.1 \%)$. The majority of newspaper readers reported tabloids as their main paper (41.1\%), compared to just over a third (38.5\%) indicating broadsheets as their main paper. Just over one-fifth (20.4\%) of respondents reported that they did not read a newspaper (including online). Fewer than one-fifth (14.4\%) reported knowledge of a child of a friend or family member being sexually groomed in their lifetime.

Three measures asked respondents to rank the prevalence of CMSG, FSG and LSG. Respondents were significantly more likely to perceive CMSG as more prevalent compared to FSG and LSG ( $x^{2}$ "656.48(2), p"B.000). Subgroup analysis revealed that media crime information source was not significant in relation to any type of grooming. However, the type of paper read was significant for both CMSG and LSG, with tabloid readers more likely to perceive higher levels of prevalence. The type of paper did not emerge as significant for FSG. Knowledge of a grooming victim was only significant in relation to FSG and LSG*those with knowledge expressing higher prevalence. Level of internet experience was not significant for any type. Several control variables also emerged as significant, including sex for all three types (females more likely to perceive higher prevalence) and parent for CMSG and FSG (nonparents more likely to perceive higher prevalence in relation to the former, and parents in relation to the latter). Household income also emerged as significant in relation to CMSG and FSG, as did age. Ethnicity emerged as significant only in relation to FSG, with Caucasians more likely to perceive higher prevalence.

Perceived safety of potential grooming spaces. Table II details the bivariate analysis of the grooming spaces variables. Three grooming spaces were identified: CM sites (such as social networking sites, chatrooms, etc.), the home and public spaces. Respectively, these correspond to the categories specified earlier: CMSG, FSG and LSG. Respondents were significantly more likely to perceive CM sites as least safe, compared to all other spaces ( $x^{2} " 792.38_{(2)}$, $\left.\mathrm{p} " \mathrm{~B} .000\right)$. Subgroup analysis revealed that media-related variables were significant only in relation to the public spaces variable, where tabloid readers were more likely to disagree that these spaces were safe. Knowledge of a child of a friend or family member who had been groomed only approached conventional levels of significance for the home. Those who knew a child who had been groomed were more likely to disagree that the home was safe. Internet expertise failed to emerge as significant in all cases. However, several of the control variables emerged as highly significant, including sex in relation to CM sites and public spaces (females more likely to disagree that these spaces were safe), parents in relation to all spaces (parents more likely to disagree) and age in relation to $\mathrm{CM}$ and public spaces (generally older respondents more likely to disagree). Household income also emerged as significant in relation to the home; however, no discernible pattern could be extrapolated from 
Table II. Bivariate statistics — respondent characteristics by perceived safety of CM, familial and localised spaces $(\mathrm{n}=557)$.

\begin{tabular}{|c|c|c|c|c|c|c|c|}
\hline \multirow[b]{2}{*}{ Independent variables } & \multirow[b]{2}{*}{ Coding } & \multirow{2}{*}{$\frac{\text { CM sites }}{\text { Mean }(1-4)}$} & \multirow[t]{2}{*}{$\mathrm{M}-\mathrm{W} / \mathrm{K}-\mathrm{W} \mathrm{Z} / \chi^{2}(\mathrm{df})$} & \multirow{2}{*}{$\begin{array}{l}\text { The home } \\
\text { Mean }(1-4)\end{array}$} & \multirow[t]{2}{*}{$\mathrm{M}-\mathrm{W} / \mathrm{K}-\mathrm{W} \mathrm{Z} / \chi^{2}(\mathrm{df})$} & \multirow{2}{*}{$\begin{array}{l}\text { Public spaces } \\
\text { Mean }(1-4)\end{array}$} & \multirow[t]{2}{*}{$\mathrm{M}-\mathrm{W} / \mathrm{K}-\mathrm{W} \mathrm{Z} / \chi^{2}(\mathrm{df})$} \\
\hline & & & & & & & \\
\hline \multirow[t]{3}{*}{ Crime info. source } & $1=$ newspapers & 2.83 & $1.72(2)$ & 1.40 & $.13(2)$ & 2.36 & $2.51(2)$ \\
\hline & $2=$ television & 2.98 & & 1.41 & & 2.42 & \\
\hline & $3=$ personal experience & 3.00 & & 1.38 & & 2.38 & \\
\hline \multirow[t]{3}{*}{ Newspaper } & $0=$ tabloid & 2.93 & $2.01(2)$ & 1.44 & $3.43(2)^{\star}$ & 2.36 & $14.14(2)^{* * *}$ \\
\hline & $1=$ broadsheet & 2.90 & & 1.35 & & 2.25 & \\
\hline & $2=$ do not read a paper & 3.05 & & 1.47 & & 2.38 & \\
\hline \multirow[t]{2}{*}{ Knowledge of grooming } & $0=$ no & 2.93 & $-1.05(1)$ & 1.38 & $-1.57(1)^{\star}$ & 2.38 & $-1.16(1)$ \\
\hline & $1=$ yes & 3.01 & & 1.53 & & 2.46 & \\
\hline \multirow[t]{2}{*}{ Ethnicity } & $0=\mathrm{BME}$ & 2.56 & $-2.28(1)^{\star *}$ & 1.32 & $-.81(1)$ & 2.40 & $-.13(1)$ \\
\hline & $1=$ white & 2.96 & & 1.41 & & 2.39 & \\
\hline \multirow[t]{2}{*}{ Sex } & $0=$ female & 3.05 & $-4.49(1)^{\star * *}$ & 1.40 & $-.30(1)$ & 2.44 & $-2.54(1)^{\star * *}$ \\
\hline & $1=$ male & 2.71 & & 1.41 & & 2.28 & \\
\hline \multirow[t]{2}{*}{ Children } & $0=$ no & 2.83 & $-4.67 * * *$ & 1.36 & $-1.79(1)^{\star \star}$ & 2.34 & $-1.75(1)^{\star \star}$ \\
\hline & $1=$ yes & 3.17 & & 1.46 & & 2.46 & \\
\hline \multirow[t]{5}{*}{ Household income } & $1=$ Below $10 \mathrm{k}$ & 2.87 & $3.72(4)$ & 1.37 & $12.31(4)^{* \star *}$ & 2.33 & $4.36(4)$ \\
\hline & $2=10-20 \mathrm{k}$ & 3.01 & & 1.53 & & 2.42 & \\
\hline & $3=20-40 \mathrm{k}$ & 2.93 & & 1.37 & & 2.44 & \\
\hline & $4=40-60 \mathrm{k}$ & 3.03 & & 1.51 & & 2.30 & \\
\hline & $5=60 \mathrm{k}$ and above & 2.86 & & 1.27 & & 2.36 & \\
\hline \multirow[t]{3}{*}{ Age } & $1=16-21$ & 2.88 & $4.89(2)^{\star \star}$ & 1.40 & $.51(2)$ & 2.33 & $9.58(2)^{\star \star \star}$ \\
\hline & $2=22-35$ & 2.90 & & 1.38 & & 2.29 & \\
\hline & $3=36$ and above & 2.94 & & 1.42 & & 2.50 & \\
\hline Internet experience & Range $=0-10$ & - & $5.80(9)$ & - & $6.68(9)$ & - & $6.04(9)$ \\
\hline
\end{tabular}

${ }^{\star} p=<.10 ;{ }^{\star \star} p=<.05 ;{ }^{\star \star \star} p<.01$.

BME: black and minority ethnic; CM: computer-mediated. 
the data. Finally, ethnicity emerged as significant in relation the CM sites, with those identifying as black and minority ethnic (BME) more likely to agree that these spaces were safe. However, given the limited number of BME respondents in the sample, this finding should be interpreted with a degree of caution.

\section{Methods of estimation and models}

Ordinal logistic regression analysis ${ }^{10}$ was conducted to determine associations between the predictor and dependent variables (perceived grooming prevalence and perceived safety of potential grooming spaces). Results from correlational analyses (not shown), and tolerance statistics and variance inflation factors showed that there were no problems with multi-collinearity among the independent variables. All models met the assumption of parallel lines required for ordinal regression. In all cases model statistics (Pearson and deviance) indicated a robust fit to the data ${ }^{11}$.

Perceived prevalence of $C M$ and localised grooming. Table III reports the results of the ordinal logistic regression performed for the three measures of perceived sexual grooming prevalence. Holding all other factors constant, primary media crime information source emerged as a highly significant predictor in both CMSG and LSG models. Log-odds ratios show that respondents who receive most of their information about crime from television media were around one-and-a-half times more likely to perceive higher levels of both CMSG and LSG compared to those who gained their information from newspapers. The type of newspaper read approached conventional levels of significance only in relation to CMSG. Holding all other factors constant, tabloid readers were just under one-and-a-half times more likely to perceive higher levels of CMSG prevalence compared to broadsheet readers. Media-related variables were not significant at predicting perceived prevalence in relation to FSG. Knowledge of a child who had been groomed emerged as a significant predictor in relation to FSG and LSG. Holding all other factors constant, log-odds ratios indicate that those with knowledge were almost one-and-ahalf times more likely to perceive higher prevalence levels of LSG and FSG compared to those without knowledge. Level of internet expertise did not emerge as a significant predictor in any of the models. Of the control variables, sex, parent and income all emerged as significant predictors. Females were nearly twice as likely to perceive higher prevalence levels for all types of grooming compared to males. Further, non-parents were nearly twice as likely to perceive higher prevalence levels in relation to CMSG compared to parents, and those on lower incomes were marginally more likely to perceive higher levels of prevalence in relation to LSG compared to those on higher incomes. Age emerged as a significant predictor only in relation to FSG, with older respondents more likely to perceive higher prevalence. Of the test variables, source of crime information emerged as the most consistent predictor across the CMSG and LSG models, while knowledge of a child of a friend or family who had been groomed emerged as a strong predictor for LSG and FSG.

To confirm the impact of the sets of test variables in isolation, three submodels (media, knowledge and internet experience) were run with the control variables for all types of grooming ${ }^{12}$. Comparing the log-likelihoods of the three submodels revealed that the media-related measures were the most important category of variables in determining higher levels of perceived prevalence of CMSG, whereas knowledge of a grooming victim variable was most important in determining higher levels of perceived prevalence of FSG and LSG ${ }^{13}$.

Perceived safety of potential grooming spaces. Table IV reports the results from the ordinal logistic regression performed on the four potential grooming spaces variables. What is first apparent is that media-related variables are significant predictors for only two spaces: CM sites and public 
Table III. Ordered regression predicting perceptions of CMSG, FSG and LSG commonality.

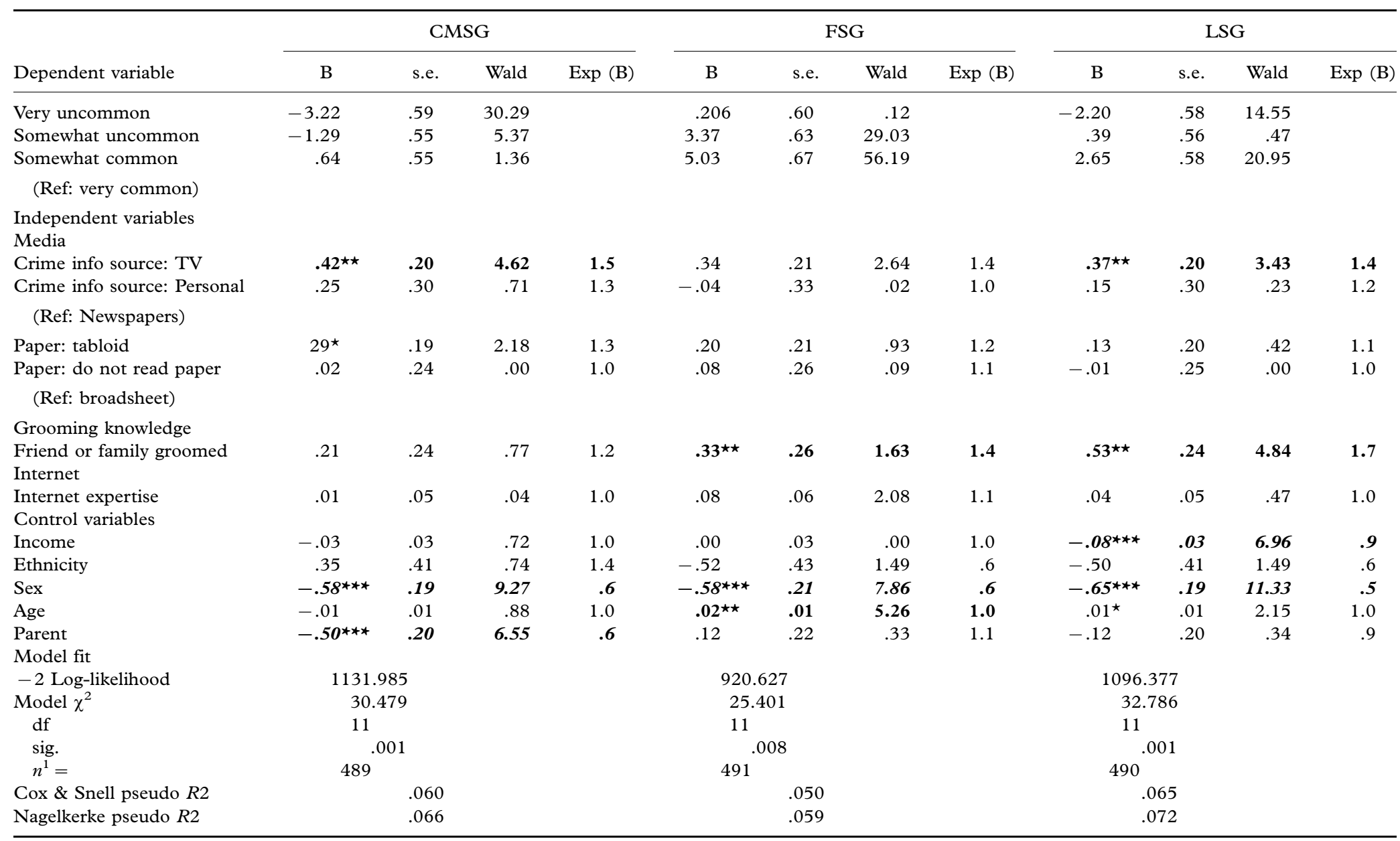

${ }^{1}$ Reduction in sample size due to listwise deletion of cases necessary for regression requirements. CMSG: computer-mediated sexual grooming; FSG: familial sexual grooming; LSG: localised sexual grooming; s.e.: standard error.

${ }^{\star} p<.10 ;{ }^{\star \star} \boldsymbol{p}<.05 ;{ }^{\star \star \star} \boldsymbol{p}<.01$. 
Table IV. Ordered regression predicting perceived safety of CM, familial and localised spaces.

\begin{tabular}{|c|c|c|c|c|c|c|c|c|c|c|c|c|}
\hline \multirow[b]{2}{*}{ Dependent variable } & \multicolumn{4}{|c|}{$\mathrm{CM}$ sites are $\mathrm{Safe}$} & \multicolumn{4}{|c|}{ The home is safe } & \multicolumn{4}{|c|}{ Public spaces are safe } \\
\hline & B & s.e. & Wald & $\operatorname{Exp}(B)$ & B & s.e. & Wald & $\operatorname{Exp}(B)$ & B & s.e. & Wald & $\operatorname{Exp}(\mathrm{B})$ \\
\hline Agree & -3.31 & .65 & 26.00 & & 2.26 & .66 & 11.65 & & -1.97 & .61 & 10.58 & \\
\hline Tend to agree & .09 & .56 & .03 & & 3.96 & .68 & 33.55 & & -1.61 & .59 & 7.34 & \\
\hline \multicolumn{13}{|l|}{ (Reference: disagree $^{\mathrm{a}}$ ) } \\
\hline \multicolumn{13}{|l|}{$\begin{array}{l}\text { Independent variables } \\
\text { Media }\end{array}$} \\
\hline Crime info source: TV & $.37^{\star \star}$ & .20 & 3.46 & 1.4 & .07 & .23 & .10 & 1.1 & .16 & .21 & .57 & 1.2 \\
\hline $\begin{array}{l}\text { Crime info source: personal } \\
\text { (Ref: newspapers) }\end{array}$ & .26 & .30 & .75 & 1.3 & -.23 & .36 & .40 & .8 & -.12 & .33 & .14 & .9 \\
\hline Paper: tabloid & .03 & .20 & .02 & 1.0 & .23 & .23 & 1.05 & 1.3 & $.53^{\star \star \star}$ & .21 & 6.26 & 1.7 \\
\hline $\begin{array}{l}\text { Paper: do not read paper } \\
\text { (Ref: broadsheet) }\end{array}$ & .10 & .24 & .18 & 1.1 & .30 & .28 & 1.14 & 1.3 & $.72^{\star \star \star}$ & .26 & 7.86 & 2.1 \\
\hline $\begin{array}{l}\text { Grooming knowledge } \\
\text { Friend or family groomed } \\
\text { Internet }\end{array}$ & .31 & .24 & 1.64 & 1.4 & $.47^{\star \star}$ & .26 & 3.19 & 1.6 & .30 & .25 & 1.45 & 1.4 \\
\hline $\begin{array}{l}\text { Internet expertise } \\
\text { Control variables }\end{array}$ & $.08^{\star}$ & .05 & 2.21 & 1.1 & .14 & .06 & 5.09 & 1.2 & .02 & .06 & .17 & 1.0 \\
\hline Income & $-.05^{\star}$ & .03 & 2.33 & 1.0 & $-.11^{\star \star \star}$ & .04 & 7.37 & .9 & .00 & .03 & .01 & 1.0 \\
\hline Ethnicity & $-.67^{\star}$ & .41 & 2.68 & .5 & -.39 & .51 & .58 & .7 & .23 & .43 & .29 & 1.3 \\
\hline Sex & $-.72^{\star \star \star}$ & .19 & 14.11 & .5 & -.01 & .22 & .00 & 1.0 & $-.37 \star \star$ & .21 & 3.18 & .7 \\
\hline Age & $.01^{\star}$ & .01 & 1.82 & 1.0 & $.02^{\star \star}$ & .01 & 3.46 & 1.0 & $.01 \star \star$ & .01 & 2.86 & 1.0 \\
\hline Parent & $.64^{\star \star \star}$ & .20 & 10.36 & 1.9 & $.35^{\star}$ & .22 & 2.40 & 1.4 & .04 & .21 & .03 & 1.0 \\
\hline \multicolumn{13}{|l|}{ Model fit } \\
\hline-2 Log-likelihood & \multicolumn{3}{|c|}{1058.656} & & \multicolumn{3}{|c|}{756.541} & \multicolumn{5}{|c|}{969.402} \\
\hline Model $\chi^{2}$ & \multicolumn{3}{|c|}{47.583} & & \multicolumn{2}{|c|}{24.242} & & \multicolumn{5}{|c|}{22.520} \\
\hline df & \multicolumn{3}{|c|}{11} & & \multicolumn{2}{|c|}{11} & & \multicolumn{5}{|c|}{11} \\
\hline sig. & \multicolumn{3}{|c|}{.000} & & \multicolumn{2}{|c|}{.012} & & \multicolumn{5}{|c|}{.021} \\
\hline $\mathrm{n}^{1}=$ & \multicolumn{2}{|c|}{$491^{.000}$} & & & \multicolumn{2}{|c|}{$488^{\circ}$} & & \multicolumn{5}{|c|}{490} \\
\hline Cox \& Snell pseudo R2 & \multicolumn{3}{|c|}{.092} & & \multicolumn{3}{|c|}{.048} & \multicolumn{5}{|c|}{.045} \\
\hline Nagelkerke pseudo R2 & \multicolumn{3}{|c|}{.103} & & \multicolumn{3}{|c|}{.061} & \multicolumn{5}{|c|}{.052} \\
\hline
\end{tabular}

${ }^{1}$ Reduction in sample size due to listwise deletion of cases necessary for regression requirements. CM: computer-mediated.

${ }^{\star} p<.10 ;{ }^{\star \star} \boldsymbol{p}<.05 ;{ }^{\star \star \star} \boldsymbol{p}=<.01$.

'Reference is 'tend to disagree' for home is safe model due to zero respondents selecting 'disagree'. 
spaces. Both these spaces were identified by respondents as the least safe in relation to sexual grooming in the earlier bivariate analysis. In relation to CM spaces, holding all other factors constant, the type of primary media crime information source emerges as a highly significant predictor. Log-odds ratios show that respondents who derive their crime information from television media are nearly one-and-a-half times more likely to disagree that $\mathrm{CM}$ sites are safe in relation to sexual grooming compared to respondents who derive their crime information from newspapers. In relation to public spaces, type of paper emerges as a highly significant predictor. Log-odds ratios indicate that readers of tabloids and non-paper readers are around twice as likely to disagree that public spaces are safe with regard to sexual grooming, compared to broadsheet readers. Neither knowledge of a child being groomed nor internet experience emerged as significant predictors for these spaces. However, the latter approached conventional levels of significance for $\mathrm{CM}$ sites. Several control variables emerged as significant predictors. For CM sites, both sex and parent significantly predicted disagreement. Holding all other factors constant, women and parents were twice as likely to disagree that these spaces were safe compared to men and non-parents. Similarly, women were nearly one-and-a-half times more likely than men to disagree that public spaces were safe. Being a parent was not a significant predictor in relation to this space. Finally, age emerged as a significant predictor, with younger people nearly one-and-a-half times more likely to disagree public spaces were safe with regard to sexual grooming.

Media variables were not significant in the home model. Conversely, holding all other factors constant, knowledge of a child of a friend or family member who had been groomed emerged as a highly significant predictor. Log-odds ratios indicate that respondents who know a grooming victim were just over one-and-a-half times more likely to disagree that the home is safe. Several control variables also emerged as significant predictors, including income, age and ethnicity. Log-odds ratios show that those on lower incomes are marginally more likely to disagree that the home is safe, as are older respondents.

As in the prevalence models, we confirmed the impact of the sets of test variables in isolation via three submodels (media, knowledge and internet experience) for each of the potential grooming spaces ${ }^{14}$. Comparing the log-likelihoods of the three submodels revealed that the media-related measures were the most important category of variables in determining higher levels disagreement in relation to the safety of $\mathrm{CM}$ sites and public spaces, while the knowledge of a grooming victim variable is most important in determining higher levels disagreement in relation to the home.

\section{Discussion}

The six models in this paper provide the first quantitative evidence in the United Kingdom indicating that the media and personal knowledge/experience have significant predictive impacts upon the perceptions of some various forms of sexual grooming. Models on the perceived prevalence of sexual grooming confirmed our first hypothesis, that media-related factors have a significant predictive capacity in relation to the public's perceived prevalence of CMSG and LSG (type of primary media news source). Furthermore, in the absence of any media effect, knowledge of a grooming victim was a significant predictor in the FSG model, confirming the second hypothesis. Counter to our postulation, this variable was also highly significant in the LSG model, and proved a better fit to the data when media and knowledge submodels were compared. There is then mixed evidence on the impact of the media in relation to the perceived prevalence of sexual grooming. While media factors are highly 
significant in relation to perceptions of prevalence of CMSG, they have less impact upon the public's perceptions of prevalence in relation to the remaining types of sexual grooming.

Understanding why the above factors have such strong predictive effects is difficult to propose without further evidence. Based on previous research (Farrell \& Soothill, 2001; McCartan, 2010; Sampson, 1994; Silverman \& Wilson, 2002; Soothill \& Walby, 1991), it is possible that over-reporting and a disproportionate focus on stranger and online sexual grooming stories accounts for the impact of media-related factors in predicting the perceived prevalence of CMSG and LSG. This would also account for the absence of media-related factors in predicting increased perceived prevalence of FSG, given that research indicates that the media avoid covering non-stranger sexual abuse stories (Ost, 2009). The inherent difficulties of recognising face-to-face grooming, particularly cases of intrafamilial and quasi-intrafamilial abuse, also need to be considered. In such cases, the offender-victim interaction will mean that many victims will not recognise that they are being groomed. Consequently, it is extremely unlikely that this type of grooming will, if at all, be discovered before the child has been physically abused, and is thus unlikely to be the focus of any news stories (Gillespie, 2004; Ost, 2004). This is supported further by the knowledge of a grooming victim variable emerging as a predictive factor in relation to FSG. It is possible, therefore, that when a member of the public receives information first hand (i.e. not from the media), it is usually in relation to grooming of a familial nature. However, this was also the case for LSG. Evidently, further qualitative research is required to understand the public's perceived inter-relationships between these types of grooming.

The models on perceived safety of potential grooming spaces also provided evidence in support of our third and fourth hypotheses. Confirming the third hypothesis, we found that media-related variables (respectively, type of primary media news source and type of paper read) had a significant negative impact upon respondents' perceptions of the safety of $\mathrm{CM}$ and localised (public) spaces. Confirming the fourth hypothesis, we found knowledge of a grooming victim best predicted disagreement to the belief that the home was safe in relation to sexual grooming. Put more succinctly, people felt that children were at most risk of sexual grooming within online and public spaces, and least at risk within the home. These results were also confirmed in the submodel analysis.

Once again, it is reasonable to suggest that the disproportionately high levels of media reporting of cases involving grooming over the internet and in public places would result in the public perceiving $\mathrm{CM}$ and localised spaces as unsafe. This supposition is supported by the absence of media predictors in the familial spaces model, replaced instead by the knowledge of a grooming victim factor. This further supports our argument that, where members of the public gain information about victimisation from non-media sources, this information is more likely to relate to FSG as opposed to CMSG or LSG.

Finally, and adding further support to the arguments outlined above, bivariate analysis revealed that the public were more likely to perceive CMSG as most prevalent and CM spaces as least safe. This, again, could be explained by the disproportionate over-reporting of CMSG related stories in the media. The dominance of media-related predictors and the absence of other test factors (knowledge of grooming victim and internet expertise) in the CM-related models further supports this line of argument.

\section{Conclusion}

This study quantitatively identifies variability in public concern over specific types of sexual grooming behaviours; most notably, that the public express the greatest distortions in relation 
to CMSG in terms of prevalence and safety. Corroborating previous qualitative research, this study provides evidence to support the argument that the media's coverage of stranger grooming via the internet has heightened the public's acceptance that this type of grooming presents a real and serious threat. This is reinforced by the way in which current legislation has attempted to deal with the problem of sexual grooming, specifically the limitations of the new offence to recognise and respond to all types of sexual grooming (Craven et al., 2007; Ost, 2004, 2009). The internet does, of course, pose a real danger to children. Crucially, it provides the offender with anonymity and access to an unprecedented number of potential victims. It is therefore imperative that preventative measures are put into place to protect children from the risks online. Research has shown that parents do not feel that they have adequate skills to supervise their chidden online (Livingstone \& Bober, 2004). Similarly, while research conducted by O'Connell (2002) found that the overwhelming majority of children in their sample were aware of dangers of online "strangers", a study by Davidson and Maretellozzo (2008) argued that the lessons of "stranger danger" were not being fully applied to cyberspace. Their findings clearly acknowledge the complexities and subtleties of grooming behaviours; in particular, the recognition that grooming can take place over extended periods of time, in which trust can be built up and "strangers" can become "virtual friends" (Martellozzo, 2011a, 2011b).

Despite the persistent media emphasis on CMSG, grooming is not restricted to online behaviour. This study has also highlighted concern over face-to-face grooming. Repeating findings in previous research, the public in our sample were more likely to express concern in relation to "stranger danger" and the threat of LSG. This is not that surprising, given the disproportionate focus in the media on abuse outside the home and family network. Craven et al. (2007, p. 67) acknowledge that "people feel safer believing that strangers pose a greater risk to their children than those they trust and love". Similarly, Ost (2009, p. 18) concludes that "stranger danger" is "easier to tackle than sexual abuse which occurs in the home".

Perhaps one of the most significant distortions expressed by the public in this study was the perceived low prevalence of FSG and of the safety of the home in relation to sexual grooming. Contrary to this widespread belief, research shows that sexual abuse is more likely to occur within the home and by someone who is known to the victim (Car, 2004; Flatley et al., 2010; Stop it Now, 2003). Consequently, sexual grooming is not restricted to strangers, although the methods, acts, behaviours and tactics used may differ. Our confirmation that the public express too little concern over familial sexual grooming supports the argument that public should be made more aware of the distinctions between types of sexual grooming behaviours, settings and offenders.

Reasserting the conclusions made by Craven et al. (2007, p. 297) "a fuller understanding of sexual grooming is therefore required [that takes into account the] offender-victim interaction [and] behaviours that may indicate to significant adults that a child is being sexually groomed, or indeed that they themselves are being groomed by an offender". To enact this necessitates a move away from current media (and legislative) rhetoric that focuses on the dangers of stranger grooming, rather than sexual grooming in its wider sense.

\section{Notes}

1. For a full account of this legislation as well as misinterpretations of what the law can and cannot do, see Craven, Brown, and Gilchrist, 2007; Gillespie, 2004; Ost, 2004

2. This includes webpages accessed via mobile phone, but not text messages or telephone calls. See McCartan and McAlister (2011) for an overview of mobile phone use and sexual abuse. 
3. For example, the CEOP thematic assessment into localised grooming identifies the importance of mobile phones in the grooming process (CEOP, 2011).

4. Online idiolect refers to the specific language patterns formed by internet users which differ from the offline spoken and written word (Williams, 2006).

5. See http://www.survey.bris.ac.uk/

6. More than 40 Cardiff University students distributed the link to the online survey via their facebook pages, yielding a significant return with a wide geographical profile (the average number of connections per student was 254). Students were also instructed to send the link via email to family and friends who, in turn, distributed the link to work colleagues, significantly boosting the age range of respondents. Finally, the authors distributed the link via the Mumsnet and Netmums forums to boost numbers of respondents with children.

7. Where population estimates are provided they should be interpreted with a degree of caution.

8. See: https://aoir.org/documents/ethics-guide/

9. The majority of those reporting personal experience as their main source of crime information also reported employment in criminal justice-related fields.

10. This type of regression analysis is the most appropriate given the data type in each of the dependent variables (ordinal data).

11. Results from the tests for parallel lines, model fit statistics and multicollinearity diagnostics are not shown. Pseudo $\mathrm{R}^{2}$ statistics are presented in Tables III and IV.

12. Data not presented in this paper but available upon request.

13. This conclusion was reached by examining the pseudo $R^{2}$ values of each submodel. For a discussion of the use of pseudo $R^{2}$ see Aldrich and Nelson (1984).

14. Data not presented in this paper but available upon request.

\section{References}

Brayford, J. \& Deering, J. (2012). Media influences on public perceptions of sex offenders. In J. Bradford, F. Cowe \& J. Deering (Eds). Sex offenders: Punish, help, change or control? Theory, policy and practice explored (pp. 52-68). London: Routledge.

Brown, S., Deakin, J., \& Spencer, J. (2008). What people think about the management of sex offenders in the Community. Howard Journal of Criminal Justice, 47, 259-274.

Carr, J. (2004). Child abuse, child pornography and the internet. London: NCH, The Children's Charity.

Child Exploitation and Online Protection (CEOP) (2011). Out of mind, out of sight: Breaking down the barrier to understanding child sexual exploitation. London: Child Exploitation and Online Protection Centre.

Craven, S., Brown, S., \& Gilchrist, E. (2006). Sexual grooming of children: Review of literature and theoretical considerations. Journal of Sexual Aggression, 3, 287-299.

Craven, S., Brown, S. J., \& Gilchrist, E. (2007). Current responses to sexual grooming: Implications for prevention. Howard Journal of Criminal Justice, 46, 60-71.

Davidson, J. (2008). Child sexual abuse: Media Representations and government reactions. London: Routledge-Cavendish.

Davidson, J., \& Gottschalk, P. (2011). Internet child abuse: Current research and policy. London: Routledge-Cavendish.

Davidson, J., \& Martellozzo, E. (2008). Protecting children online: Towards a safer internet. In G. Letherby,

K. Williams, P. Birch \& M. Cain (Eds). Sex as crime? (pp. 338-355). Cullompton: Willan.

Dorofeev, S., \& Grant, P. (2006). Statistics for real-life sample surveys: Non-simple random samples and weighted data. Cambridge: Cambridge University Press.

Farrell, P., \& Soothill, K. (2001). Television documentaries on sex offenders: The emergence of a new genre? Police Journal, 74, 6167.

Fielding, N., Lee, R., M., \& Black, G. (2008). The SAGE handbook of online research methods. London: Sage.

Finkelhor, D. (1984). Child sexual abuse: New theory and research. New York: Free Press.

Flatley, J., Smith, K., Chaplin, R., \& Moon, D. (2010). Crime in England and Wales 2009/10: Findings from the British Crime Survey and Police Recorded Crime, 3rd edn. London: Home Office.

Gillespie, A. (2004). Tackling grooming. Police Journal, 77, 239.

Greer, C. (2003). Sex crime and the media. Cullompton: Willan.

Hall, G. C. N., \& Hirschman, R. (1992). Sexual aggression against children: A conceptual perspective of etiology. Criminal Justice and Behavior, 19, 8-23.

Hudson, K. J. (2005). Offending identities: Sex offenders' perspectives of their treatment and management. Cullompton: Willan.

Jewkes, Y. (2010). Much ado about nothing? Representations and realities of online soliciting of children. Journal of Sexual Aggression, 16, 5-18. 
Jewkes, Y. (2004). Media and crime. London: Sage.

Jewkes, Y. (2007). Crime online. Cullompton: Willan.

Joinson, A. N. (1998). Causes and effects of disinhibition on the internet. In J. Gackenbach (Ed.). The psychology of the internet (pp. 43-60). New York: Academic Press.

Kitzinger, J. (2004). Framing abuse: Media influence and public understandings of sexual violence against children. New York: Pluto.

Livingstone, S. \& Bober, M. (2004). UK children go online: Surveying the experiences of young people and their parents. London: LSE Report (launched 21 July 2004).

Levenson, J. S., Brannon, Y. N., \& Baker, J. (2007). Public perceptions about sex offenders and community protection policies. Analysis of Social Issues and Public Policy, 7, 1-15.

Martellozzo, E. (2011a). Understanding the perpetrators' online behaviour. In J. Davidson \& P. Gottschalk (Eds). Internet child abuse: Current research and policy (pp. 104-125). London: Routledge.

Martellozzo, E. (2011b). Online child sexual abuse: Grooming, policing and child protection in a multi-media world. London: Routledge.

McAlinden, A. M. (2006). "Setting 'em up': Personal, familial and institutional grooming in the sexual abuse of children. Social and Legal Studies, 15, 339-362.

McCarten, K. (2004). "HERE THERE BE MONSTERS": The public's perception of paedophiles with particular reference to Belfast and Leicester. Medicine, Science and the Law, 44, 327-342.

McCartan, K. F. (2010). Media constructions and reactions to paedophilia in modern society. In K. Harrison (Ed.). Dealing with high-risk sex offenders in the community: Risk management, treatment and social responsibilities (pp. 249 -

268). Cullompton: Willan.

McCartan, K. \& McAlister, R. (2011). Mobile phone technology and sexual abuse. Paper presented at The Welsh Centre for Crime and Social Justice Annual Conference 2011, Gregynog, Wales.

Meyer, I. H., \& Wilson, P. A. (2009). Sampling lesbian, gay, and bisexual populations. Journal of Counseling Psychology, 56, $23-31$.

Mohan, J., Twigg, L., \& Taylor, J. (2011). Mind the double gap: Using multivariate multilevel modelling to investigate public perceptions of crime trends. British Journal of Criminology, 51, 1035-1053.

O'Connell, R. (2001). Be somebody else but be yourself at all times: Degrees of identity deception in chat rooms. Cyberspace Research Unit. Available at: B http://www.once.uclan.ac.uk/print/deception_print.htm! (accessed September 2011).

O’Halloran, E., \& Quayle, E. (2010). A content analysis of a "boy love” support forum: Revisiting Durkin \& Bryant. Journal of Sexual Aggression, 16, 71-85.

Olver, M. E., \& Barlow, A. A. (2010). Public attitudes toward sex offenders and their relationship to personality traits and demographic characteristics. Behavioral Sciences and the Law, 28, 832-849.

Ost, S. (2004). Getting to grips with sexual grooming? The new offence under the Sexual Offences Act 2003. Journal of Social Welfare and Family Law, 26, 147-159.

Ost, S. (2009). Child pornography and sexual grooming: Legal and societal responses. Cambridge: Cambridge University Press.

Proctor, J. L., Badzinski, D. M., \& Johnson, M. (2002). The impact of media on knowledge and perceptions of Megan's Law. Criminal Justice Policy Review, 13, 356-379.

Quayle, E. (2008). Sex offenders on the internet. Applied Cognitive Psychology, 22, 1320-1321.

Reiner, R. (2007). Media made criminality: The representation of crime in the mass media. In M. Maguire, R. Morgan \& R. Reiner (Eds). The Oxford handbook of criminology (pp. 302-337). Oxford University Press: Oxford.

Sampson, A. (1994). Acts of abuse. London: Routledge.

Schiavone, S. K., \& Jeglic, E. L (2009). Public perception of sex offender social policies and the impact on sex offenders. International Journal of Offender Therapy and Comparative Criminology, 53, 679-695.

Silverman, J., \& Wilson, D. (2002). Innocence betrayed: Paedophilia, the media and society. Cambridge: Polity Press. Soothill,

K., \& Walby, S. (1991). Sex crimes in the news. London: Routledge.

Stop it Now (2003). What we all need to know to protect our children. Available at: B http://www.stopitnow.org.uk/files/ protect $\% 20$ our $\% 20$ children.pdf? (accessed September 2011).

Sullivan, J., \& Beech, A. (2002). Professional perpetrators: Sex offenders who use their employment to target and sexually abuse the children with whom they work. Child Abuse Review, 11, 153-167.

Taylor, M. \& Quayle, E. (2008). Criminogenic qualities of the internet in the collection and distribution of abuse images of children. Irish Journal of Psychology, 29(2), 119-130.

Thakker, J. (2012). Public attitudes to sex offenders in New Zealand. Journal of Sexual Aggression: An international, interdisciplinary forum for research, theory and practice, 18(2), 149-163.

Ward, T. (2002). Marshall and Barbaree's integrated theory of child sexual abuse: A critique. Psychology, Crime and Law, 8, 209228. 
Ward, T., \& Siegert, R. (2002). Toward a comprehensive theory of child sexual abuse: A theory knitting perspective.

Psychology, Crime and Law, 8, 319-351.

Ward, T., Hudson, S. M., \& Marshall, W. L. (1995). Cognitive distortions and affective deficits in sex offenders: A cognitive deconstructionist interpretation. Sexual Abuse: Journal of Research and Treatment, 7, 67-83.

Webster, S., Davidson, J., \& Bifulco, A. (2011). European Online Grooming Project Annual Report. Brussels: European Commission Safer Internet Plus Programme.

Webster, S., Davidson, J., Bifulco, A., Gottschalk, P., Caretti, V., Pham, T., \& Grove-Hills, J. (2010). European Online Grooming Project, Scoping Report. Brussels: European Commission Safer Internet Plus Programme.

Williams, M. (2006). Virtually criminal: Crime, deviance and regulation online. London: Routledge.

Wolf, S. C. (1984). A model of sexual aggression/addiction. Journal of Social Work and Human Sexuality, 7, 131-148.

Zamble, E., \& Kalm, K. L. (1990). General and specific measures of public attitudes towards sentencing. Canadian Journal of Behavioural Science, 22, 327-337.

Zilney, L. J., \& Zilney, L. A. (2009). Reconsidering sex crimes and offenders: Prosecution or persecution?. Santa Barbara, CA: Praeger. 